\title{
Original Article \\ Efficacy and Safety Assessment of T. Angelica Herbal Tonic, a Phytomedicinal Product Popularly Used in Nigeria
}

\author{
Charles O. Esimone, ${ }^{1}$ Peter A. Akah, ${ }^{2}$ and Chukwuemeka S. Nworu' \\ ${ }^{1}$ Department of Pharmaceutics, Faculty of Pharmaceutical Sciences, University of Nigeria, \\ Nsukka 410001, Enugu State, Nigeria \\ ${ }^{2}$ Department of Pharmacology \& Toxicology, Faculty of Pharmaceutical Sciences, University of Nigeria, \\ Nsukka 410001, Enugu State, Nigeria \\ Correspondence should be addressed to Chukwuemeka S. Nworu, csnworu@yahoo.com
}

Received 28 February 2009; Accepted 13 September 2009

Copyright (C) 2011 Charles O. Esimone et al. This is an open access article distributed under the Creative Commons Attribution License, which permits unrestricted use, distribution, and reproduction in any medium, provided the original work is properly cited.

\begin{abstract}
T. Angelica Herbal Tonic (TAHT) is a herbal product indicated for indigestion and constipation and highly patronized in Nigeria. In this study, the efficacy and safety of the herbal tonic in relation to the label claims were assessed. The effect on peristalsis in mice was evaluated by the charcoal meal model and in vitro using guinea pig ileum. The effects of TAHT on behavior, fertility, birth and organ weights were also determined. Teratogenic potential and reproductive toxicity were studied in pregnant rats. Acute toxicity studies showed that at doses above $5000 \mathrm{mg} \mathrm{kg}^{-1}$, the herbal tonic did not cause lethality and produced no signs of intoxication in mice. The study did not show any gross behavioral changes in mice treated with $1000 \mathrm{mg} \mathrm{kg}^{-1}$ of TAHT as compared with the negative control treatment. TAHT $\left(400 \mathrm{mg} \mathrm{kg}^{-1}\right)$ exhibited a dose-dependent enhancement in the gastrointestinal tract motility in mice when compared with the negative control. At concentrations up to $300 \mu \mathrm{g} \mathrm{mL} \mathrm{L}^{-1}$, TAHT did not cause any significant effect on acetylcholine, histamine and nicotine-evoked contractions of guinea pig ileum preparation. It took an average of $31.25 \pm 4.52$ days for the TAHT-treated animals to litter, which is significantly $(P<.05)$ different from the $55 \pm 4.51$ days recorded for the control treatment group. TAHT exhibited a modest fertility-promoting effect and showed lack of abortifacient and teratogenic properties in the study. Generally, the results of this study showed some favorable pharmacological effects of TAHT in animals which may authenticate some of the label claims.
\end{abstract}

\section{Introduction}

Historically, herbal medicine has been an important component of healthcare all over the world. With the advances in medical and biological sciences that resulted in the introduction of promising synthetic orthodox therapies for many conditions, the use of herbal medicine declined in the 20th century. Lately, however, there has been a resurgence of interest in the use of phytomedicinal products in the treatment of diseases $[1,2]$. The World Health Organization (WHO) has documented the rapidly growing interest and economic importance of Traditional Medicine (TM) in health systems all over the world.

In Africa, a WHO report estimated that up to $80 \%$ of the population use TM to help meet their health care needs either alone or in combination with orthodox therapies $[3,4]$. Asian and Latin American populations continue to use
$\mathrm{TM}$ as a result of historical circumstances and cultural beliefs. In China, TM accounts for $\sim 40 \%$ of all health care services delivered. In many developed countries, complementary and alternative medicines (CAMs) is also becoming more and more popular. The percentage of the population which has used CAM at least once is $48 \%$ in Australia, $70 \%$ in Canada, $42 \%$ in USA, $38 \%$ in Belgium and $75 \%$ in France. In many parts of the world, expenditure on TM/CAM is not only significant, but also growing rapidly. In Australia, Canada and the UK, annual CAM expenditure is estimated at US\$ 80 , US\$ 2400 and US $\$ 2300$ million, respectively $[5,6]$.

With the increasing popularity and patronage of commercially promoted herbal medications, the need for the assessment of the safety and quality of these products is increasingly being felt. The safety evaluation of herbal products is even more important since the popular belief that herbal therapies are without untoward effects have 
often been proven incorrect [7, 8]. Assurances of safety, efficacy and quality of herbal medicines have been limited by lack of research methodology, inadequate evidence base for TM/CAM therapies and products, lack of international and national standards, lack of adequate regulation and registration of herbal medicines, lack of registration of TM/CAM providers and inadequate support for such research efforts $[9,10]$.

T. Angelica Herbal Tonic (TAHT) is an amber-colored liquid preparation with slight bitter taste, packaged in $750 \mathrm{~mL}$ amber colored plastic bottle. TAHT is promoted as a mild laxative with: "aids digestion", "relieves constipation", "eliminates bloatness", and "enhances bowel cleansing" as key label indications. TAHT is labeled to contain Doundake root $(3.71 \%)$ and Cassia acutifolia $(1.0 \%)$ as the active ingredients and Kalii nitras $(0.073 \%)$, Methyl paraben $(0.2 \%)$, Propyl paraben $(0.02 \%)$ and deionized water as inactive ingredients. This herbal product is highly patronized in Nigeria and is claimed to be useful for a variety of purposes by the public. This stimulated the interest in conducting an investigation into the safety and efficacy of the products in relation to the claim of this product using laboratory animal models.

\section{Materials and Methods}

2.1. The Product. TAHT is an amber colored liquid preparation with a slightly bitter taste. It is packaged in an amber plastic bottle of $750 \mathrm{~mL}$ capacity, closed with a tamperproof aluminum screw cap. Each $150 \mathrm{~mL}$ of the preparation contains Doundake root obtained from Nauclea latifolia ( $5.56 \mathrm{~g}$, equivalent to $2.36 \mathrm{mg} / \mathrm{mL}$ total alkaloid) and $C$. acutifolia leaf ( $1.5 \mathrm{~g}$, equivalent to $3.075 \%$ sennoside $\mathrm{B})$. In this study, the dosing of the TAHT to animals was based on the total active ingredient content per milliliter of the tonic.

Permission to undertake the study was obtained from the manufacturer, HErBALINE Nigeria Ltd, and samples used in the study were obtained from the manufacturer's direct supply chain.

2.2. Animals. Adult albino rats (100-200 g), albino mice (21$25 \mathrm{~g}$ ) and guinea pigs (220-280 g) of both sexes, obtained from the Laboratory Animal Facility of the Department of Pharmacology and Toxicology, University of Nigeria, Nsukka were used in the study. The animals were housed under standard conditions $\left(25 \pm 2^{\circ} \mathrm{C}\right.$ and 12 -h light/dark cycle $)$. The rats and mice were maintained on standard pellets (Livestock feed), while guinea pigs were fed with guinea grass (Panicum maximum L.). All animals were allowed unrestricted access to drinking water. The use and care of laboratory animals in the study were in accordance with the ethical guidelines contained in the European Convention for the Protection of Vertebrate Animals used for Experimental and Other Scientific Purposes (EEC Directive of 1986; 86/609/EEC) as amended in the European Treaty Series (ETS no. 170) of 2005 .

2.3. Acute Toxicity Determination. The acute toxicity study of TAHT was assessed by oral administration in albino mice using the Lorke (1983) method [11]. Briefly, the tests involved two phases. The first phase is the determination of the toxic range. The mice were placed in three groups $(n=$ 3 ) and were administered TAHT (10, 100 and $\left.1000 \mathrm{mg} \mathrm{kg}^{-1}\right)$ orally. The treated mice were observed for $24 \mathrm{~h}$ for the number of deaths. The death pattern in the first phase determined the doses used for the second phase according to the Lorke (1983) estimation [11]. In this phase, four groups $(n=3)$ of mice were used for each dose. Each group received different doses of the TAHT (p. o.) as predetermined in the first phase and the animals were observed for lethality or signs of acute intoxication for $24 \mathrm{~h}$. The $\mathrm{LD}_{50}$ was calculated as the geometric mean of the highest nonlethal dose and the least toxic dose.

2.4. Gastrointestinal Tract Motility. The primary indication of the herbal tonic is for bowel cleansing, relief of constipation and mild purgation. This necessitated the investigation of the effect of the TAHT on gastrointestinal (GI) motility. Sixteen albino mice of either sex (20-30 g), randomly divided into four groups $(n=4)$ were used in the study. The animals were starved for $24 \mathrm{~h}$ prior to the experiment, but were allowed unrestricted access to drinking water. The first two groups received 200 and $400 \mathrm{mg} \mathrm{kg}^{-1}$, respectively, while the $3 \mathrm{rd}$ and 4 th groups received carbachol $\left(40 \mathrm{mg} \mathrm{kg}^{-1}\right)$ and normal saline $\left(10 \mathrm{~mL} \mathrm{~kg}^{-1}\right)$. After $5 \mathrm{~min}$ of drug administration, $0.5 \mathrm{~mL}$ of $5 \%$ charcoal dispersion in tragacanth mucilage was administered orally to each animal. The animals were sacrificed $30 \mathrm{~min}$ later and the abdomen opened. The percentage distance traveled by the charcoal plug in the small intestine (from the pylorus to the caecum) in the treatment groups were determined and compared with the normal saline-treated group used as the negative control.

2.5. Neuropharmacological Activity. Ten mice placed into two groups $(n=5)$ were used in the study. The first group was given TAHT (1000 $\mathrm{mg} \mathrm{kg}^{-1}$, p.o.) and the second group served as the control and was given normal saline (20 $\mathrm{mL} \mathrm{kg}^{-1}$, p.o.). The treated animals were observed for $24 \mathrm{~h}$ and behavioral parameters (including awareness, mood, motor activity, central activity, muscle tone, reflexes and autonomic effects) were monitored.

2.6. Reproductive and Developmental Toxicity Investigation. These studies assessed TAHT for abortifacient, teratogenic and deleterious developmental effects. Virgin rats were divided into two groups $(n=5)$ and acclimatized for 15 days. During this time, the test group was given oral dose of TAHT $\left(500 \mathrm{mg} \mathrm{kg}^{-1}\right)$ daily $(\sim 10$ times the daily recommended dose of $60 \mathrm{mg} \mathrm{kg}^{-1}$ ), while the control group daily received $5 \mathrm{~mL} \mathrm{~kg}^{-1}$ of distilled water orally. The animals were monitored for normal growth and development. After this period, two mature male rats of proven fertility (based on earlier ability to cause pregnancies) were introduced into each cage and the number of days that elapsed before delivery was recorded for the rats in each group. During gestation, the rats were monitored for incidences of possible spontaneous abortion. The birth weight of litters, sex (determined 3 weeks 
TABLE 1: The effect of acute dose of TAHT $\left(1000 \mathrm{mg} \mathrm{kg}^{-1}\right)$ on the behavioral pattern of mice.

\begin{tabular}{|c|c|c|c|}
\hline Bahavioral activity & Description & Control treatment score ${ }^{\mathrm{a}}$ & Test treatment scores ${ }^{\mathrm{a}}$ \\
\hline \multirow[t]{2}{*}{ Awareness } & Alertness & 4 & 4 \\
\hline & Passivity & 0 & 1 \\
\hline \multirow[t]{4}{*}{ Mood } & Grooming & 4 & 4 \\
\hline & Vocalization & 0 & 0 \\
\hline & Fearfulness & 0 & 0 \\
\hline & Aggressiveness & 0 & 0 \\
\hline \multirow[t]{3}{*}{ Motor activity } & Inquisitive behavior in unfamiliar environment & 0 & 0 \\
\hline & Touch response & 4 & 4 \\
\hline & Pain response & 4 & 4 \\
\hline \multirow[t]{3}{*}{ Central activity } & Response to noise & 4 & 4 \\
\hline & Tremor & 0 & 0 \\
\hline & Convulsion & 0 & 0 \\
\hline \multirow[t]{2}{*}{ Muscle tone } & Limb tone & 4 & 4 \\
\hline & Grip strength & 4 & 4 \\
\hline \multirow[t]{2}{*}{ Reflexes } & Pinna reflex & 4 & 4 \\
\hline & Cornea reflex & 4 & 4 \\
\hline \multirow[t]{3}{*}{ Autonomic effects } & Respiratory rate & 4 & 4 \\
\hline & Piloerection & 0 & 0 \\
\hline & Writhing & 0 & 0 \\
\hline
\end{tabular}

${ }^{\mathrm{a}}$ The scores were recorded on a scale of $0-8$ with a base score of a normal response as 4 .

TABLE 2: Effects of TAHT on gastrointestinal motility in mice.

\begin{tabular}{lcc}
\hline Agents & Dose $\left(\mathrm{mg} \mathrm{kg}^{-1}\right)$ & Percentage of intestinal transit \\
\hline Carbachol & 40 & $73.03 \pm 5.72^{*}$ \\
Normal saline & $20 \mathrm{~mL} \mathrm{~kg}^{-1}$ & $56.02 \pm 6.88$ \\
TAHT & $200 \mathrm{mg} \mathrm{kg}^{-1}$ & $65.90 \pm 4.02$ \\
TAHT & $400 \mathrm{mg} \mathrm{kg}^{-1}$ & $70.93 \pm 2.71^{*}$ \\
\hline
\end{tabular}

Albino mice were placed randomly into four groups and were starved for $24 \mathrm{~h}$ prior to the experiment. The first two groups received 200 and $400 \mathrm{mg} \mathrm{kg}^{-1}$ of the TAHT, respectively, while the $3 \mathrm{rd}$ and 4 th groups received carbachol $\left(40 \mathrm{mg} \mathrm{kg}^{-1}\right)$ and normal saline $\left(10 \mathrm{~mL} \mathrm{~kg}^{-1}\right)$. After $5 \mathrm{~min}$ of drug administration, $0.5 \mathrm{~mL}$ of $5 \%$ charcoal dispersion in tragacanth mucilage was administered orally to each animal. The animals were sacrificed $30 \mathrm{~min}$ later and the percentage of distance traveled by the charcoal plug in the small intestine (from the pylorus to the caecum) were determined and compared with the negative control.

* Significant $P<.05$ versus control.

after birth) and total number of litters were recorded. The litters were also observed for incidences of malformation. Daily oral administration of TAHT continued while animals were lactating. The litters were also observed for growth and development for a period of 3 weeks. At the end of the study, the adult female rats were sacrificed and gross morphological examinations carried out on the major organs (heart, lungs, spleen, liver and kidney); the weights of the organs were also determined.

\subsection{In Vitro Pharmacological Experiments}

2.7.1. Guinea Pig Ileum Activity. This study was conducted to determine the effects of TAHT on the smooth muscle of GIT. Segments of ileum isolated from freshly sacrificed

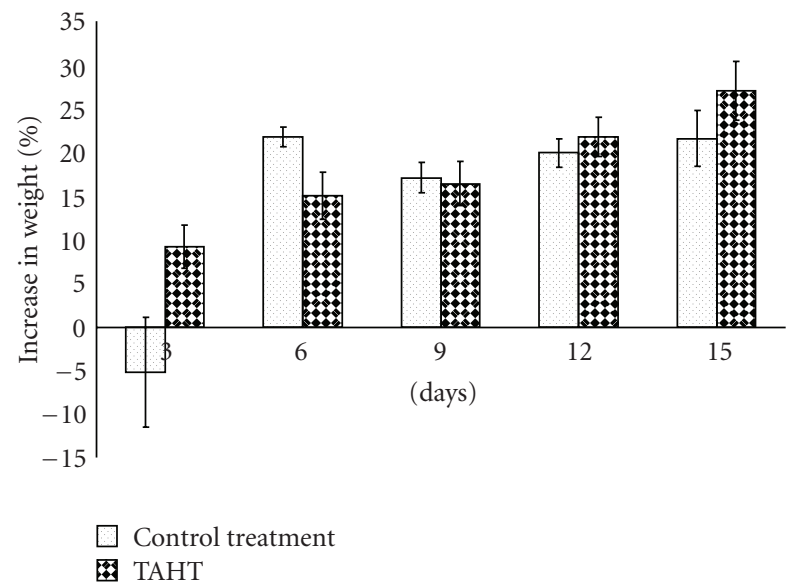

FIGURE 1: Increase in weight of virgin rats during the administration of THAT before mating.

guinea pig were suspended in $30 \mathrm{~mL}$ organ bath containing Tyrode's solution at $37 \pm 1^{\circ} \mathrm{C}$ aerated with air. The effect of TAHT on the isolated tissue was studied according to classical methods. Increasing concentrations of TAHT up to $300 \mu \mathrm{g} \mathrm{mL}^{-1}$ were added into the organ bath to determine its effect on isolated ileum. The effect of TAHT on contractions produced by standard agonists: acetylcholine $\left(0.3 \mu \mathrm{g} \mathrm{mL}^{-1}\right)$, histamine $\left(0.06 \mu \mathrm{g} \mathrm{mL}^{-1}\right)$ and nicotine $\left(30 \mu \mathrm{g} \mathrm{mL}^{-1}\right)$ were also studied.

2.7.2. Gravid Rat Uterus Activity. The possible effect of TAHT on intrinsic rhythmic contraction of isolated gravid uterus, and therefore the assessment of possible tocolytic or 
TABLE 3: Summary of reproductive effects of TAHT in experimental rats.

\begin{tabular}{|c|c|c|}
\hline Parameter & Control group & Test group \\
\hline Number of virgin rats & 5 & 5 \\
\hline Percentage of pregnancy at the end of experiment & 80 & 80 \\
\hline Percentage of pregnant by the 43 rd day & 0 & 80 \\
\hline Percentage of pregnant by the 65 th day & 80 & 80 \\
\hline Mean number of days elapsed before delivery & $55.00 \pm 4.71$ & $31.25 \pm 4.52^{*}$ \\
\hline Total litter size & 21 & 30 \\
\hline Average litter size & $5.25 \pm 0.95$ & $7.50 \pm 0.50$ \\
\hline Number of male litters & 10 & 16 \\
\hline Number of female litters & 11 & 14 \\
\hline Average birth weight (g) & $5.95 \pm 0.10$ & $4.81 \pm 0.19^{*}$ \\
\hline Percentage increase in weight 21 days after birth & $364.53 \pm 10.01$ & $390.74 \pm 34.47$ \\
\hline \multicolumn{3}{|c|}{ Percent weight of major organs (relative to body weight) } \\
\hline (i) Heart & $0.463 \pm 0.024$ & $0.358 \pm 0.017^{*}$ \\
\hline (ii) Kidney & $0.639 \pm 0.037$ & $0.595 \pm 0.020$ \\
\hline (iii) Lung & $0.646 \pm 0.020$ & $0.750 \pm 0.022$ \\
\hline (iv) Spleen & $0.297 \pm 0.024$ & $0.304 \pm 0.008$ \\
\hline (v) Liver & $5.185 \pm 0.147$ & $4.17 \pm 0.152^{*}$ \\
\hline \multicolumn{3}{|c|}{ Duration of pregnancy (days) in each of the four pregnancies achieved in both groups (counting from the start of mating) } \\
\hline (i) First animal & 46 & 21 \\
\hline (ii) Second animal & 48 & 30 \\
\hline (iii) Third animal & 61 & 31 \\
\hline (iv) Fourth animal & 65 & 43 \\
\hline
\end{tabular}

${ }^{*}$ Significant $P<.05$ versus control.



$\square$ Control

图 Test

FIGURE 2: Percentage increase in the weight of the litters over a 21day monitoring period.

abortifacient properties was also determined. The two horns of uterus isolated from a freshly sacrificed gravid rat were cut longitudinally into strips. A strip was mounted in De Jalon's solution and the effect of increasing concentrations of TAHT on the spontaneous rhythmic contraction of the uterine strip was monitored.

2.8. Statistical Analysis. Data were analyzed by analysis of variation, ANOVA using SPSS (version 11) and differences

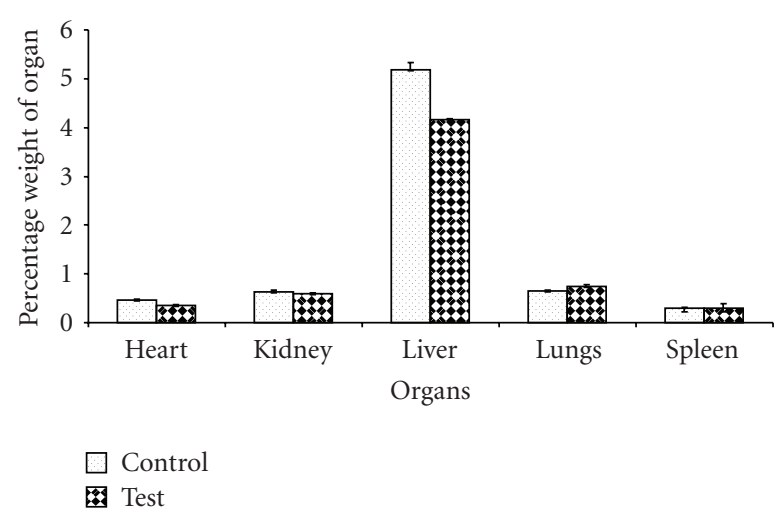

Figure 3: Percentage weight of the organs (relative to the body weight) of the rats after sacrifice.

between paired observations were regarded as significant at $P \leq .05$.

\section{Results}

3.1. Toxicity of TAHT. At doses above $5000 \mathrm{mg} \mathrm{kg}^{-1}$, the herbal tonic did not cause lethality and produced no signs of acute intoxication in the mice. Therefore, TAHT could generally be regarded as safe. The study did not show any 


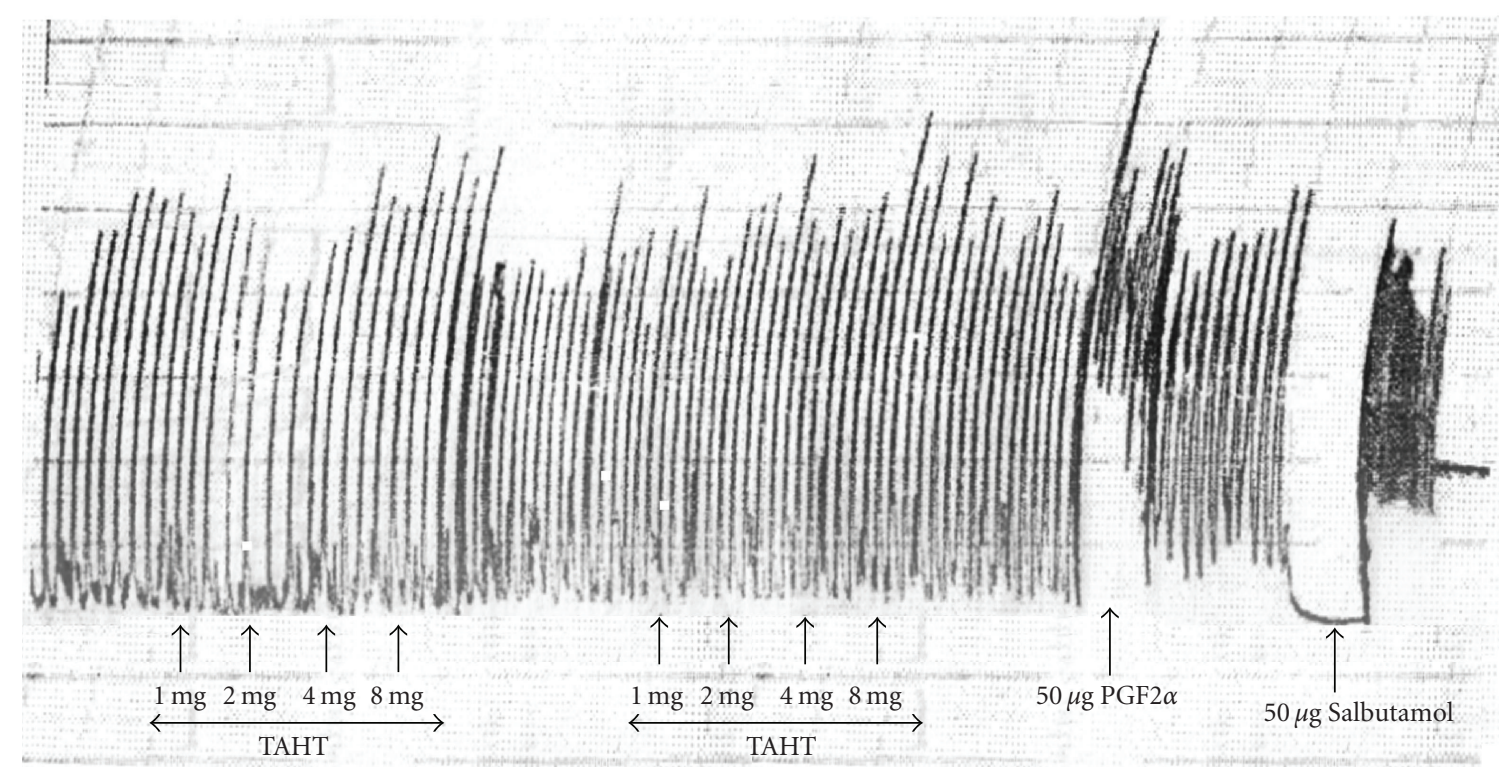

FIGURE 4: The effect of THAT (cumulative) on intrinsic contractility of the gravid rat uterus. A sample tracing showing the treatment of rat uterine strips with increasing amount of (1-8 mg) of THAT, PGF2 $\alpha$ and Salbutamol. THAT did not affect the frequency and amplitude of uterine strips inherent contractility.

gross behavioral changes in mice treated with $1000 \mathrm{mg} \mathrm{kg}^{-1}$ of TAHT as compared with the negative control treatment (Table 1).

3.2. TAHT Improves GIT Motility. The TAHT exhibited a dose-dependent enhancement in the GI tract (GIT) motility in mice. The increase in the intestinal motility induced by the higher dose $\left(400 \mathrm{mg} \mathrm{kg}^{-1}\right)$ was significant $(P<$ .05) when compared with the negative control; however, the effect was slightly below the increase in peristalsis produced by carbachol $40 \mathrm{mg} \mathrm{kg}^{-1}$, a standard muscarinic agonist (Table 2). Addition of TAHT at concentrations up to $300 \mu \mathrm{g} \mathrm{mL}^{-1}$ did not produce any significant effect on acetylcholine, histamine and nicotine-evoked contractions of guinea pig ileum preparation.

\subsection{Reproductive and Developmental Activity of TAHT.} There was no significant difference $(P>.05)$ in the increase in the weight of the virgin rats treated with TAHT and the control treatment after a 15-day monitoring period (Figure 1). It also took an average of $31.25 \pm 4.52$ days for the test (treated) animals to litter. This is significantly $(P<.05)$ different from the $55 \pm 4.51$ days that elapsed before delivery was recorded for the control treatment group. By the 43rd day of mating, $80 \%$ of the rats in the test group had delivered while none delivered in the control group (Table 3). The mean weight of the litters in the control group $(5.95 \pm 0.09 \mathrm{~g})$ was found to be significantly higher $(P<.05)$ than that of the test group $(4.81 \pm 0.19 \mathrm{~g})$ (Figure 2$)$. The mean number of litters was $7.50 \pm 0.05$ and $5.25 \pm 0.95$ in the test and control groups, respectively (Table 3 ). Subsequent monitoring of the litters in both groups showed that there was no significant difference in the percentage increase in weight over the 21day observation period (Table 3 and Figure 2), indicating lack of developmental effect on lactating animals (Table 3 ).

No spontaneous abortion or malformation was noted in any of the pregnant rats and litters in both groups. The results indicate that TAHT lacks abortifacient and teratogenic properties. Gross morphological examination of the major organs showed no difference in the organs from both the control and the test animals. However, significant differences $(P<.05)$ were noted in the mean weight of the heart and liver, where higher mean values were recorded for the control group animals (Figure 3 ).

3.4. Activity of TAHT on Uterine Strips. TAHT did not modify the intrinsic contractility of isolated uterine preparations. In the experiment, salbutamol (a tocolytic agent) completely relaxed the uterine strip while prostaglandin $\mathrm{F}_{2 \alpha}\left(\mathrm{PGF}_{2 \alpha}\right)$, a typical abortifacient, also caused sustained increase in amplitude and frequency of the uterine muscle strip contraction (Figure 4).

\section{Discussion}

In the study on mice, TAHT with $\mathrm{LD}_{50}>5000 \mathrm{mg} \mathrm{kg}^{-1}$ could be considered safe [11]. Although safety studies in animal models could often be extrapolated to humans, it does not necessarily follow that such products would be completely safe in humans. Therefore, actual controlled clinical trials on human subjects would be more definitive evidence on safety. TAHT did not cause the contraction of guinea pig ileum preparation and did not produce any significant effect on acetylcholine, histamine and nicotine-evoked contractions of the tissue. This result suggests that the pro-kinetic effect of 
TAHT on GIT may not be mediated by a direct effect on muscarinic, histaminergic or nicotinic receptors stimulation. Although the laxative effect of TAHT recorded in the whole animal experiments could support the benefits claimed in the use of TAHT for indigestion, constipation and bloating of stomach, the exact mechanism by which TAHT induces increase in the intestinal motility is not clear from the study.

The lower mean birth weights recorded in the group treated with TAHT could be ascribed to the higher number of litter size (a total of 30 for test group and 21 for control group), since higher multiple pregnancy could lead to lower mean birth weights. Subsequent monitoring of the litters in both groups showed that there was no significant difference in the percentage increase in weight over 21-day observation period, indicating lack of developmental effect on lactating animals. Although the study demonstrates some fertility promotion effect of TAHT, more studies will be required to definitively confirm any possible effect on sexuality, fertility and fertility hormones. The study also showed that TAHT lacks abortifacient and teratogenic effects.

TM and CAM are now attracting increasing attention and many governments are now according relevance to CAM in the provision of health care all over the world [12]. Some important issues must be addressed if the potentials of TM/CAM are to be developed successfully. It is known that herbs in their natural state vary in potency and may contain multiple pharmacological substances which can cause undesirable effects. In most instances, herbal medicines are not made with isolated and purified active substance that will permit standardization of dosages, and testing for safety and efficacy before approval [13]. Some toxic reactions to the use of herbal remedies are related to improper preparation, excessive quantities of some herbs, substitution of a herb with related herbs believed to possess similar effects and the effect of using herbal medications concomitantly with other pharmacologic products $[14,15]$.

In this study, a scientific assessment of a highly patronized herbal preparation marketed and used in Nigeria was undertaken. The results of this study show some level of efficacy and safety, which are related to some of the claimed indications of the phytomedicine. The results also showed some favorable pharmacological effects in animal models, which authenticates some of the label claims. However, further exhaustive studies, especially in human volunteers, would be necessary to succinctly validate the safety and efficacy of this herbal tonic.

\section{Funding}

Personal finances of the authors.

\section{References}

[1] P. Fisher and A. Ward, "Medicine in Europe: complementary medicine in Europe," British Medical Journal, vol. 309, no. 6947, pp. 107-111, 1994.

[2] D. M. Eisenberg, R. B. Davis, S. L. Ettner et al., "Trends in alternative medicine use in the United States, 1990-1997: Results of a follow-up national survey," Journal of the American
Medical Association, vol. 280, no. 18, pp. 1569-1575, 1998.

[3] World Health Organization, "Promoting the role of traditional medicine in health systems: a strategy for the African region 2001-2010," Harare, Zimbabwe, World Health Organization, (AFR/RC50/Doc.9/R), 2000.

[4] K. Hostettmann and A. Marston, "Twenty years of research into medicinal plants: results and perspectives," Phytochemistry Reviews, vol. 1, no. 3, pp. 275-285, 2002.

[5] D. F. Foster, R. S. Phillips, M. B. Hamel, and D. M. Eisenberg, "Alternative medicine use in older Americans," Journal of the American Geriatrics Society, vol. 48, no. 12, pp. 1560-1565, 2000.

[6] World Health Organization, "Traditional Medicine Strategy (2002-2005),” WHO/EDM/TRM/2002.1, 2002.

[7] J. Ness, F. T. Sherman, and C. X. Pan, "Alternative medicine: what the data say about common herbal therapies," Geriatrics, vol. 54, no. 10, pp. 33-43, 1999.

[8] S. B. A. Halkes, "Safety issues in phythotherapy," in Herbal Medicine: A Concise Overview for Professionals, E. Ernst, Ed., p. 82, Elsevier, Amsterdam, The Netherlands, 2000.

[9] P. C. Pietroni, "Beyond the boundaries: relationship between general practice and complementary medicine," British Medical Journal, vol. 305, no. 6853, pp. 564-566, 1992.

[10] World Health Organization, "Consultation Meeting on Traditional Medicine and Modern Medicine: Harmonizing the Two Approaches," Geneva, Switzerland, World Health Organization, TM/ICP/TM/001/RB/98-RS/99/GE/32(CHN), 1999.

[11] D. Lorke, "A new approach to practical acute toxicity testing," Archives of Toxicology, vol. 54, no. 4, pp. 275-287, 1983.

[12] World Health Organization, "Regulatory Situation of Herbal Medicines: A Worldwide Review," Geneva, Switzerland, : World Health Organization, WHO/TRM/98.1, 1998.

[13] F. L. Bishop and G. T. Lewith, "Who uses CAM? A narrative review of demographic characteristics and health factors associated with cam use," Evidence-Based Complementary and Alternative Medicine, vol. 7, no. 1, pp. 11-28, 2008.

[14] V. M. Shinde, K. Dhalwal, K. R. Mahadik, K. S. Joshi, and B. K. Patwardhan, "RAPD analysis for determination of components in herbal medicine," Evidence-Based Complementary and Alternative Medicine, vol. 4, no. 1, pp. 21-23, 2007.

[15] W. B. Jonas, "Alternative medicine-learning from the past, examining the present, advancing to the future," Journal of the American Medical Association, vol. 280, no. 18, pp. 1616-1618, 1998. 




The Scientific World Journal
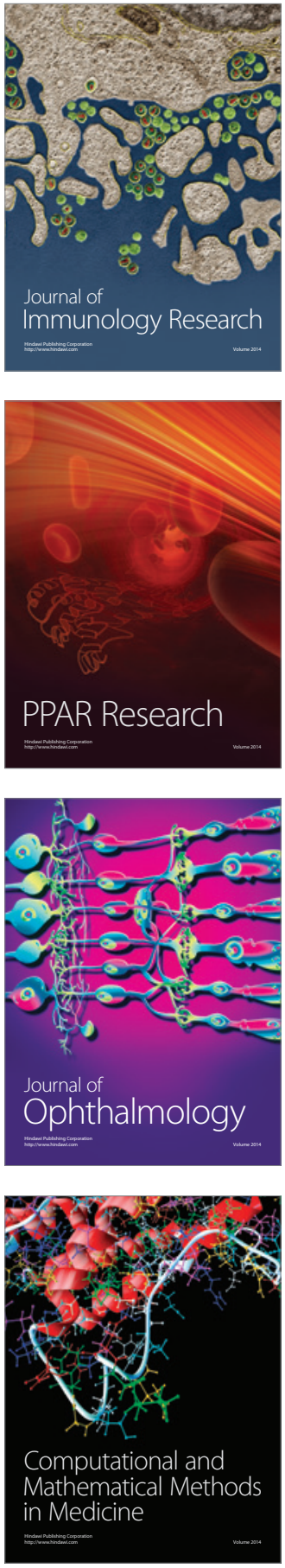

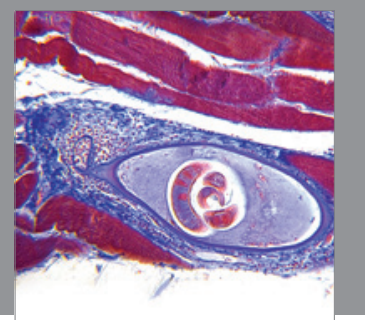

Gastroenterology

Research and Practice
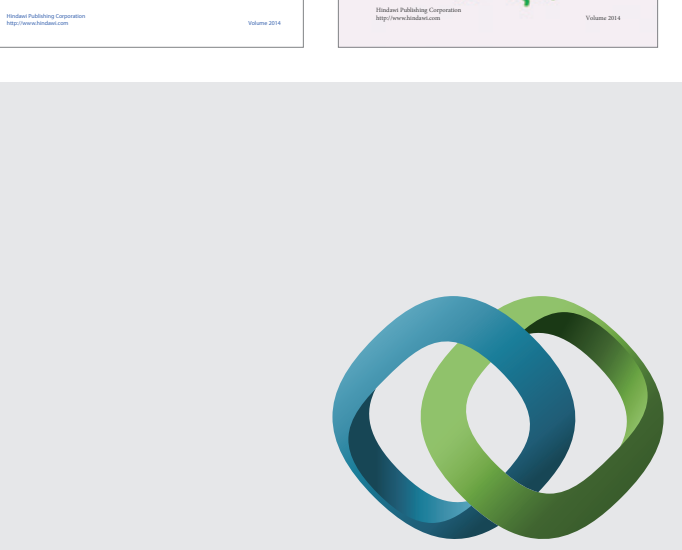

\section{Hindawi}

Submit your manuscripts at

http://www.hindawi.com


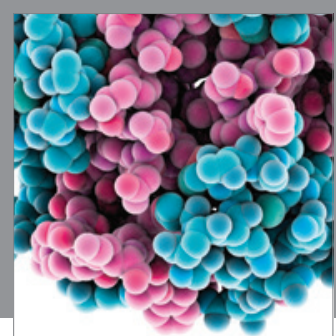

Journal of
Diabetes Research

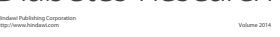

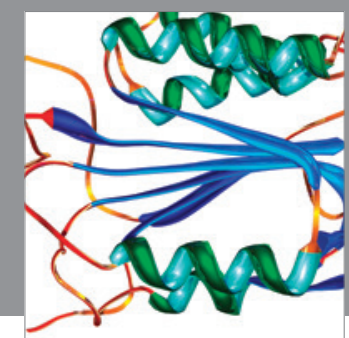

Disease Markers
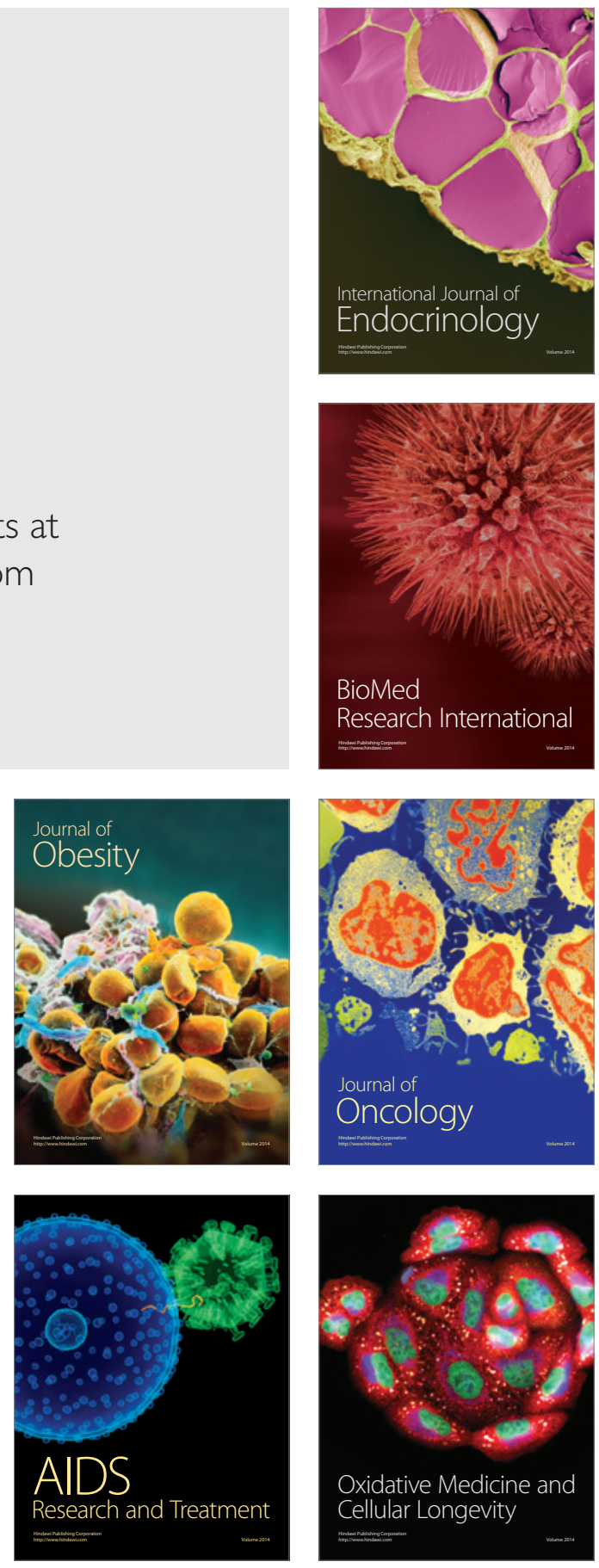